\title{
Is a sedentary lifestyle an independent predictor for hospital and early mortality after elective cardiac surgery?
}

\author{
L. Noyez $\cdot$ I. Biemans $\cdot$ M. Verkroost $\cdot$ H. van Swieten
}

Published online: 3 July 2013

(C) The Author(s) 2013. This article is published with open access at Springerlink.com

\begin{abstract}
Objective This study evaluates whether a sedentary lifestyle is an independent predictor for increased mortality after elective cardiac surgery.

Methods Three thousand one hundred fifty patients undergoing elective cardiac surgery between January 2007 and June 2012 completed preoperatively the Corpus Christi Heart Project questionnaire concerning physical activity (PA). Based on this questionnaire, 1815 patients were classified as active and 1335 patients were classified as sedentary. The endpoints of the study were hospital mortality and early mortality.

Results The study population had a mean age of $69.7 \pm 10.1$ (19-95) years and a mean logistic EuroSCORE risk of 5.1 $1 \pm 5.6$ (0.88-73.8). Sedentary patients were significantly older $(p=0.001)$, obese $(p=0.001)$, had a higher EuroSCORE risk $(p=0.001)$, and a higher percentage of complications. Hospital mortality $(1.1 \%$ versus $0.4 \%(p=0.014))$ and early mortality $(1.5 \%$ versus $0.6 \%(p=0.006))$ were significantly higher in the sedentary group compared with the active group. However, a sedentary lifestyle was not identified as an independent predictor for hospital mortality $(p=0.61)$ or early mortality $(p=0.70)$. Conclusion Sedentary patients were older, obese and had a higher EuroSCORE risk. They had significantly more postoperative complications, higher hospital mortality and early mortality. Despite these results, sedentary behaviour could not be identified as an independent predictor for hospital or early mortality.
\end{abstract}

L. Noyez $(\bowtie) \cdot$ I. Biemans $\cdot$ M. Verkroost $\cdot$ H. van Swieten Department of Cardio- Thoracic Surgery - 677, Heart Center, Radboud University Nijmegen Medical Center, PO Box 9101, 6500 HB Nijmegen, the Netherlands e-mail: 1.noyez@ctc.umcn.nl
Keywords Mortality $\cdot$ Cardiac surgery $\cdot$ Sedentary $\cdot$ Physical activity

\section{Introduction}

Increased levels of physical activity (PA) reduce the risk of cardiovascular disease and physically active survivors of a cardiac event have a lower risk of recurrent events [1-3]. It is also known that immobility after cardiac surgery contributes to an increased risk for postoperative complications and a longer hospital stay [4-6]. Recently, slow gait speed was identified as an independent predictor of mortality and morbidity in elderly patients undergoing cardiac surgery, whilst the EuroSCORE II identified poor mobility (secondary to musculoskeletal or neurological dysfunction) as a predictor for an increased mortality after cardiac surgery [7-9]. The aim of the current study was to evaluate whether sedentary behaviour is an independent predictor for short-term mortality after elective cardiac surgery.

\section{Patients and methods}

Patients

From our Coronary Surgery Database Radboud Hospital (CORRAD) - a database that stores pre-, peri-, and postoperative data plus follow-up data from all adult patients undergoing cardiac surgery at the Radboud University Nijmegen Medical Centre (UMCN) - we identified 4392 patients who had undergone isolated coronary artery bypass grafting $(\mathrm{CABG})$, isolated aortic valve surgery (AVR), isolated mitral valve surgery (MVR), combined aortic valve and mitral valve surgery (AMVR) whether or not in combination with CABG, between January 2007 and June 2012. For this study, 
patients undergoing isolated or combined valve surgery were grouped in the VALVE group and patients undergoing isolated CABG in the CABG group. Of the 4392 operations, 4014 (90\%) were elective and $3150(78 \%)$ of these elective patients completed a preoperative questionnaire concerning physical activity on the day before surgery. All patients who were discharged from the hospital were included in our follow-up [10]. The initial EuroSCORE [11] is used for risk stratification.

\section{Physical activity}

For assessing physical activity, criteria of The Corpus Christi Heart Project are used [3]. The five activity levels and their description are presented in Table 1. These five levels are coded from 1 (i.e. the worst level of physical activity) to 5 (i.e. the highest level). As in The Corpus Christi Heart Project, patients with code 1 and 2 are classified as sedentary, whilst the others represent the active group. In addition, as in our previous study, we converted the codes of physical activity into a metric scale [12].

All patients participated on a voluntary basis in this study. Registration of data in the CORRAD database and the use of this information for research have been approved by the local ethics and research council of the Radboud University, Nijmegen [10].

\section{Outcome variables}

In this study we included two primary endpoints. First, we used 'hospital mortality', which is defined as death occurring at any time during initial hospital admission after cardiac surgery in the cardiac surgery centre. Secondly, we examined 'early mortality', which is defined as all hospital mortalities and all deaths within 30 days postoperatively in the group of patients who were discharged from the UMCN before the 30th post-surgical day. The definitions of all other, secondary variables used in this study are summarised in Table 1.

Table 1 Categorisation of physical activity and definitions of used variables

\begin{tabular}{|c|c|c|c|}
\hline 2 activity levels & 5 activity levels & Activity description & Activity examples \\
\hline \multirow[t]{2}{*}{ Sedentary } & Sedentary & $\begin{array}{l}\text { Essentially no PA above minimum demands } \\
\text { of daily living }\end{array}$ & Watching TV, working at desk, driving car \\
\hline & Minimal & $\begin{array}{l}\text { Activity during normal daily routine, } 15-30 \mathrm{~min} / \\
\text { day, very light to fairly light exertion }\end{array}$ & $\begin{array}{l}\text { Some stair-climbing, light gardening, } \\
\text { light housekeeping, light home repairs }\end{array}$ \\
\hline \multirow[t]{3}{*}{ Active } & Mild & $\begin{array}{l}\text { Activity to exercise muscle groups, } 15-30 \mathrm{~min} / \text { day, } \\
\text { fairly light to somewhat hard exertion }\end{array}$ & $\begin{array}{l}\text { Calisthenics, lifting weights, heavy gardening, } \\
\text { heavy housekeeping }\end{array}$ \\
\hline & Moderate & $\begin{array}{l}\geq 1 \text { dynamic activities performed } 1-3 \text { times/week, } \\
15 \mathrm{~min} / \mathrm{session}, \text { marked increase in heart rate } \\
\text { or somewhat hard exertion }\end{array}$ & $\begin{array}{l}\text { Running, jogging, bicycling, fast walking, } \\
\text { dancing, tennis }\end{array}$ \\
\hline & Vigorous & $\begin{array}{l}\geq 1 \text { dynamic activities performed } 3 \text { times/week, } \\
20 \mathrm{~min} / \mathrm{session} \text {, somewhat hard to hard exertion }\end{array}$ & $\begin{array}{l}\text { Vigorous calesthenics, aerobic dancing, } \\
\text { aerobic workouts, competitive sport }\end{array}$ \\
\hline Variable & \multicolumn{3}{|l|}{ Definition } \\
\hline Pulmonary disease & \multicolumn{3}{|c|}{ Long-term use of bronchodilators or steroids for lung disease } \\
\hline Vascular pathology & \multicolumn{3}{|c|}{$\begin{array}{l}\text { Claudicatio, carotid occlusion or }>50 \% \text { stenosis, previous or planned } \\
\text { intervention on the abdominal aorta, limb arteries or carotids }\end{array}$} \\
\hline Neurological event & \multicolumn{3}{|c|}{ History of cerebrovascular accident or transischaemic attack } \\
\hline Redo-surgery & \multicolumn{3}{|c|}{ Previous cardiac surgery } \\
\hline Renal insufficiency & \multicolumn{3}{|c|}{$\begin{array}{l}\text { Increase of serum creatinine to }>200 \mu \mathrm{mol} / \mathrm{L} \& 2 \times \text { the } \\
\text { baseline creatinine level of a new requirement for dialysis }\end{array}$} \\
\hline Insulin & \multicolumn{3}{|c|}{ Insulin-dependent diabetes } \\
\hline Myocardial infarction & \multicolumn{3}{|c|}{ Preoperative history of a myocardial infarction } \\
\hline $\begin{array}{l}\text { Recent myocardial } \\
\text { infarction }\end{array}$ & \multicolumn{3}{|c|}{ Myocardial infarction $<90$ days before surgery } \\
\hline Poor left ventricular function & \multicolumn{3}{|c|}{ Left ventricular ejection fraction $<0 \%$} \\
\hline NYHA IV & \multicolumn{3}{|c|}{ New York Heart Association classification IV angina or cardiac insufficiency at rest } \\
\hline BMI & \multicolumn{3}{|c|}{ Body mass index $\left(\mathrm{kg} / \mathrm{m}^{2}\right)$} \\
\hline Reoperation & \multicolumn{3}{|c|}{ Operative reintervention for any cause } \\
\hline Stroke & \multicolumn{3}{|c|}{ Postoperative history of cerebrovascular accident and/or transischaemic attack } \\
\hline Renal insufficiency & \multicolumn{3}{|c|}{$\begin{array}{l}\text { Increase of serum creatinine to }>200 \mu \mathrm{mol} / \mathrm{L} \& 2 \times \text { the baseline creatinine } \\
\text { level of a new requirement for dialysis }\end{array}$} \\
\hline Sternal wound problems & \multicolumn{3}{|c|}{$\begin{array}{l}\text { A deep sternal infection involves muscle, bone, and/or mediastinum } \\
\text { or a sternal refixation without infection }\end{array}$} \\
\hline
\end{tabular}


Statistical analyses

Statistical analyses were performed using PASW statistics 18 SPSS Inc., Chicago, IL, USA. Baseline characteristics are presented as percentage for dichotomous variables, as mean \pm standard deviation (SD), and as a range for numerical variables. Differences in baseline characteristics between groups were assessed using the $\chi^{2}$ test or Fisher's exact test for discrete variables and the two-sample students' $t$-test for continuous variables. Physical activity was examined as an independent risk factor for hospital mortality and early mortality using binary logistic regression. The Hosmer-Lemeshow test, which is a variation of the $\chi^{2}$ statistics [13], was used for goodness of fit for the regression. A $P$-value of $\leq 0.05$ is considered significant.

\section{Results}

\section{Patients}

Between January 2007 and June 2012, 4014 elective cardiac operations were performed at the UMCN; 3150 patients (78 \%) completed the preoperative PA questionnaire. There was no statistically significant difference in age, operative risk, gender and hospital mortality between the study population and patients not included in our study (Table 2).

The study population included 2153 patients $(67.5 \%)$ in the CABG group and 997 patients (32.5\%) in the VALVE group. In the VALVE group, 439 patients underwent isolated AVR, 342 patients AVR in combination with CABG, 125 patients isolated MVR, 70 patients a combined MVR and CABG procedure and 21 patients AMVR whether or not in combination with CABG. In case of AVR, 127 mechanical valves (16\%) and 675 bioprostheses ( $84 \%)$ were implanted. In case of MVR, 23 mechanical valves (10.6\%) and 48 biological valves $(22.2 \%)$ were implanted, and 145 mitral valve reconstructions $(67.2 \%)$ were performed. In the CABG group 1927 patients $(89.5 \%)$ were operated on pump, $226(10.5 \%)$ off pump. At least one arterial graft was used in $97 \%$ of the patients in the CABG group.

Table 2 Study population versus excluded group

\begin{tabular}{llll}
\hline Variable & $\begin{array}{l}\text { Study population } \\
N=3150(\%)\end{array}$ & $\begin{array}{l}\text { Excluded group } \\
N=864(\%)\end{array}$ & $\begin{array}{l}p- \\
\text { value }\end{array}$ \\
\hline Age (years) & $68.7 \pm 10.9(19-95)$ & $68.4 \pm 10.1(24-89)$ & 0.483 \\
Female & $847(27)$ & $233(27)$ & 0.233 \\
Additive & $4.0 \pm 2.6(0-18)$ & $4.1 \pm 2.6(0-14)$ & 0.090 \\
$\quad$ EuroSCORE & & $5.19 \pm 5.3(0.88-38.4)$ & 0.101 \\
Logisitic & $5.06 \pm 5.6(0.88-73.8)$ & & \\
$\quad$ EuroSCORE & & $7(0.9)$ & 0.717 \\
Hospital mortality & $22(0.7)$ & & \\
\hline
\end{tabular}

The whole study population had a mean age of $69.7 \pm 10.1$ (19-95, median 69.4 years). A mean additive EuroSCORE of 4.0 $\pm 2.6(0-18$, median 4.0) and a mean logistic EuroSCORE risk of 5.1 $\pm 5.6(0.88-73.8$, median 3.1). The mean calculated PA was $2.7 \pm 1.0(1-5$, median 3$), 1335$ patients (42\%) were scored as sedentary, 1815 patients $(58 \%)$ as active. Hospital mortality was 22 patients $(0.68 \%)$, six patients $(0.2 \%)$ in the CABG group, and 16 patients (1.6\%) in the VALVE group. The 30-day follow-up was complete for 3141/3150 patients (99.7\%): 2145/2153 (99.6\%) in the CABG group and 996/997 (99.8 \%) in the VALVE group. Early mortality was registered in 30 patients (30/3141) $(0.95 \%), 10 / 2145(0.46 \%)$ in the CABG group and 20/996 (2.0\%) for the VALVE group.

Table 3 presents the characteristics and patient demographics for sedentary and active patients. Patients in the sedentary group have a significantly lower calculated mean PA compared with active patients $(p=0.001)$. In addition, the sedentary patients are also significantly older $(p=0.001)$, obese $(p=0.001)$, and at higher risk for risk-adjusted mortality (additive and logistic EuroSCORE) $(p=0.001)$. This sedentary group has a significantly higher percentage of the studied comorbidity risk factors with exception of redo-surgery $(p=0.082)$, and NYHA IV $(p=0.055)$. The percentage of patients with a recent myocardial infarction was significantly higher in the active group $(p=0.030)$, but the percentage of patients with a history of a myocardial infarction is not significantly different between the active and sedentary group $(p=0.210)$. Interestingly, we found no statistically significant differences for the type of operation ( $p=0.096$ ).

Table 4 presents the postoperative complications stratified for sedentary and active patients. With the exception for reoperations and postoperative stroke, the sedentary group had a significantly higher percentage of studied complications. The percentage of renal insufficiency $(p=0.030)$, sternal wound problems $(p=0.030)$, ventilation $>2$ days $(p=0.001)$, intensive care stay $>5$ days $(p=0.001)$ and the mean intensive care stay $(p=0.001)$ were significantly higher in the sedentary group compared with the active group. Hospital mortality was significantly higher in the sedentary group $(p=0.014)$ Also early mortality was statistically significant higher in the sedentary group compared with the active subjects; 20/1326 $(1.5 \%)$ versus $10 / 1815(0.6 \%)$, respectively $(p=0.006)$.

Table 5 shows the results of the binary logistic regression analysis. This regression analysis identified renal disease $(p=0.027)$, NYHA IV $(p=0.001)$, and preoperative pulmonary disease $(p=0.001)$ as independent predictors for hospital mortality. For early mortality, the model identified high-risk surgery $(p=0.047)$, preoperative renal disease $(p=0.008)$ NYHA IV $(p=0.001)$, left ventricular ejection fraction $<30 \%(p=0.034)$ and preoperative pulmonary disease $(p=0.005)$ as independent predictors. A sedentary lifestyle, however, was not identified as an independent predictor for hospital mortality $(p=0.61)$ or early mortality $(p=0.70)$. To evaluate if there is an incremental 
Table 3 Characteristics and patient demographics

\begin{tabular}{|c|c|c|c|c|}
\hline \multirow[b]{2}{*}{ Variable } & \multirow[b]{2}{*}{ Category } & \multicolumn{3}{|l|}{$N=3150$} \\
\hline & & Active $N=1815$ & Sedentary $N=1335$ & $p$-value \\
\hline Corpus Christi Heart Project* & & $3.50 \pm 0.71(3-5)$ & $1.75 \pm 0.43(1-2)$ & 0.001 \\
\hline Age (years) & & $68.0 \pm 10.0(19-93)$ & $69.7 \pm 10.0(19-95)$ & 0.001 \\
\hline \multirow[t]{3}{*}{ Age group } & $<65$ & $667(36.7)$ & $419(31.4)$ & \multirow[t]{3}{*}{0.001} \\
\hline & $\geq 65-<75$ & $665(36.6)$ & $457(34.2)$ & \\
\hline & $\geq 75$ & $483(26.6)$ & $459(34.4)$ & \\
\hline Sex & female & $366(20.2)$ & $481(36.0)$ & 0.001 \\
\hline Additive EuroSCORE & & $3.6 \pm 2.4(0-12)$ & $4.5 \pm 2.8(0-18)$ & 0.001 \\
\hline Logistic EuroSCORE & & $4.4 \pm 4.7(0.8-51.2)$ & $5.9 \pm 6.6(0.88-73.8)$ & 0.001 \\
\hline \multirow[t]{3}{*}{ Risk group } & Low & $657(36.2)$ & $351(26.3)$ & \multirow[t]{3}{*}{0.001} \\
\hline & Medium & $744(41.0)$ & $494(37.0)$ & \\
\hline & High & $414(22.8)$ & $490(36.7)$ & \\
\hline Pulmonary disease & Yes & $150(8.3)$ & $183(13.7)$ & 0.001 \\
\hline Vascular pathology & Yes & $206(11.3)$ & $276(20.7)$ & 0.001 \\
\hline Redo-surgery & Yes & $66(3.6)$ & $65(4.9)$ & 0.087 \\
\hline Renal disease & Yes & $10(0.6)$ & $29(2.2)$ & 0.001 \\
\hline Neurological event & Yes & $164(9.0)$ & $167(12.5)$ & 0.002 \\
\hline Insulin & Yes & $123(6.8)$ & $146(10.9)$ & 0.001 \\
\hline Myocardial infarction & Yes & $520(28.7)$ & $410(30.7)$ & 0.210 \\
\hline Recent myocardial infarction & Yes & $153(8.4)$ & $85(6.4)$ & 0.030 \\
\hline Poor left ventricular function & Yes & $59(3.3)$ & $64(4.8)$ & 0.027 \\
\hline NYHA IV & Yes & $94(5.2)$ & $91(6.8)$ & 0.055 \\
\hline BMI & & $27.12 \pm 3.8(16.6-53.8)$ & $28.23 \pm 4.6(13.4-48.3)$ & 0.001 \\
\hline $\mathrm{BMI}>30$ & Yes & $356(19.6)$ & $429(32.1)$ & 0.001 \\
\hline Type of surgery & Valve & $553(30.5)$ & $444(33.3)$ & 0.096 \\
\hline
\end{tabular}

Corpus Christi Heart Project* calculated values (ref 11), NYHA: New York Heart Association Class, BMI: Body Mass Index

value of active/sedentary lifestyle, the Hosmer-Lemeshow $\chi^{2}$ test was performed for the binary regression with and without the variable sedentary lifestyle. The calculated $p$-value for hospital mortality increased from 0.126 to 0.267 and for early mortality from 0.656 to 0.881 . This increase of the $p$-values suggests that the performance of the model improved after addition of the variable sedentary lifestyle. When high-risk EuroSCORE class and sedentary lifestyle are used in combination, we found that the percentage of hospital and early mortality in high-risk patients with a sedentary lifestyle is about twofold greater in patients with a sedentary lifestyle compared with high-risk patients with an active lifestyle (Fig. 1).

\section{Discussion}

Our study did not identify a sedentary lifestyle as an independent predictor for hospital mortality or early mortality after cardiac surgery. Important here is that our analysis is not biased by our a priori selection of patients, since we found no differences between our included patients and patients excluded from participation for age, gender, operative risk and percentage hospital mortality.

The sedentary group is significantly older $(p=0.001)$ and obese $(p=0.001)$. There is a significantly higher percentage of women $(p=0.001)$, patients with renal disease $(p=0.001)$, a neurological event $(p=0.002)$, pulmonary disease $(p=0.001)$, vascular pathology $(p=0.001)$, insulin-dependent diabetes $(p=0.001)$ and poor left ventricular function $(p=0.027)$. Several of these variables, for example vascular disease and pulmonary disease, are believed to contribute to sedentary behaviour. The observation that the active group demonstrated a significantly larger number of patients with a recent myocardial infarction $(p=0.03)$ may be because these patients were surprised during their 'active' life by their infarct and are therefore in the active group. Because most of these variables are also related to the operative risk $[8,11]$, the calculated EuroSCORE risk is higher for the sedentary patient population compared with the active group.

Postoperatively, the sedentary group reported a significantly higher percentage of complications, hospital mortality $(p=0.014)$, renal failure $(p=0.030)$, and sternal wound problems 
Table 4 Postoperative complications stratified for active and sedentary patients

\begin{tabular}{|c|c|c|c|c|}
\hline \multirow[b]{2}{*}{ Variable } & & \multicolumn{3}{|l|}{$N=3150$} \\
\hline & & $\begin{array}{l}\text { Active } \\
N=1815\end{array}$ & $\begin{array}{l}\text { Sedentary } \\
N=1335\end{array}$ & $P$-value \\
\hline Hospital mortality & Yes & $7(0.4)$ & $15(1.1)$ & 0.014 \\
\hline Reoperation & Yes & $105(5.8)$ & $68(5.1)$ & 0.400 \\
\hline Stroke & Yes & $9(0.5)$ & $12(0.9)$ & 0.170 \\
\hline Renal insufficiency & Yes & $32(1.8)$ & $39(2.9)$ & 0.030 \\
\hline $\begin{array}{l}\text { Sternal wound } \\
\text { problems }\end{array}$ & Yes & $10(0.6)$ & $17(1.3)$ & 0.030 \\
\hline Ventilation $>2$ days & Yes & $31(1.7)$ & $54(4.0)$ & 0.001 \\
\hline $\begin{array}{l}\text { Intensive care } \\
\text { stay (days) }\end{array}$ & Yes & $1.3 \pm 1.9(0-53)$ & $3.0 \pm 41.8(0-194)$ & 0.001 \\
\hline $\begin{array}{l}\text { Intensive care } \\
\quad \text { stay }>5 \text { days }\end{array}$ & Yes & $19(1.0)$ & $46(3.4)$ & 0.001 \\
\hline
\end{tabular}

$(p=0.030)$. Furthermore, the percentage of patients with ventilator support $>2$ days $(p=0.001)$, patients with an intensive care stay $>5$ days $(p=0.001)$ and a longer mean intensive care stay $(p=0.001)$ is significantly higher in the sedentary group. We selected these complications and their definitions because these were also used in the Quality Measurement Score of the Society of Thoracic Surgeons [14] and, therefore, benchmarking is possible. However, discussion about the definitions of complications and even preoperative risk variables is a never-ending story $[8,9,11,15,16]$. The registered early mortality is also significantly higher $(p=0.007)$ for the sedentary group compared
Percentage hospital and early mortality according to the EuroSCORE risk and lifestyle

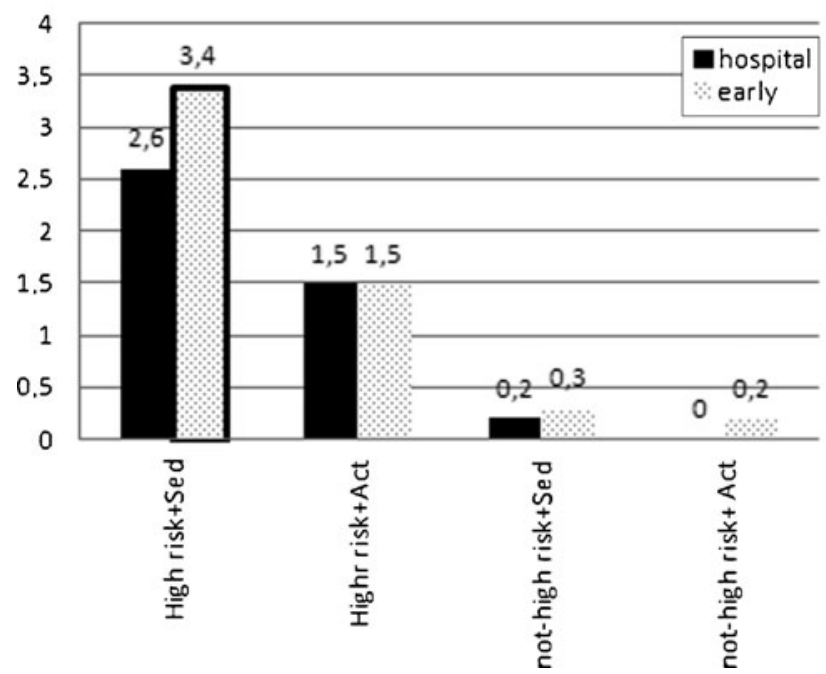

Fig. 1 Percentage hospital and early mortality according to the EuroSCORE risk and sedentary or active lifestyle

with the active group ( 20 patients, $1.5 \%$ versus 10 patients, $0.6 \%$, for the active group).

Although these results from our univariate analyses suggest that sedentary behaviour has a negative influence on postoperative morbidity and the studied mortality, our regression analysis did not identify a sedentary lifestyle as an independent predictor for hospital mortality or for early mortality. Preoperative renal disease, NYHA IV and pulmonary disease,
Table 5 Results of binary logistic regression analysis

\begin{tabular}{|c|c|c|c|c|c|}
\hline \multirow[t]{2}{*}{ tic regression analysis } & \multirow{2}{*}{$\begin{array}{l}\text { Variable } \\
\text { Variables entered in the regression model }\end{array}$} & \multicolumn{2}{|c|}{ Hospital mortality } & \multicolumn{2}{|c|}{ Early mortality } \\
\hline & & $p$-value & OR $(95 \% \mathrm{CI})$ & $p$-value & OR $(95 \% \mathrm{CI})$ \\
\hline & Old age $\geq 75$ years & 0.33 & $1.6(0.5-4.5)$ & 0.17 & $1.8(0.7-4.6)$ \\
\hline & Valve surgery & 0.12 & $2.6(0.7-9.2)$ & 0.052 & $2.7(0.9-7.6)$ \\
\hline & Female gender & 0.051 & $0.3(0.1-1.0)$ & 0.047 & $0.4(0.1-0.9)$ \\
\hline & High risk & 0.052 & $5.6(0.9-32.2)$ & 0.14 & $2.6(0.7-9.6)$ \\
\hline & Renal disease & 0.027 & $6.7(1.2-36.6)$ & 0.008 & $6.9(1.9-29.1)$ \\
\hline & $\mathrm{BMI}>30$ & 0.118 & $0.3(0.1-1.2)$ & 0.359 & $0.6(0.2-1.6)$ \\
\hline & NYHA IV & 0.001 & $7.7(2.7-22.3)$ & 0.001 & $5.7(2.2-14.5)$ \\
\hline & Insulin use & 0.054 & $3.2(0.9-10.6)$ & 0.051 & $2.6(0.9-7.2)$ \\
\hline & Vascular pathology & 0.865 & $0.9(0.2-2.9)$ & 0.70 & $0.8(0.2-2.2)$ \\
\hline & Recent myocardial infarction & 0.658 & $1.5(0.2-11.2)$ & 0.76 & $0.7(0.1-4.3)$ \\
\hline & Poor left ventricular function & 0.058 & $3.4(0.9-12.7)$ & 0.035 & $3.3(1.1-10.2)$ \\
\hline & Lung disease & 0.001 & $4.9(1.8-13.0)$ & 0.005 & $3.4(1.4-8.1)$ \\
\hline & Myocardial infarction & 0.797 & $0.9(0.2-3.3)$ & 0.32 & $1.6(0.6-4.4)$ \\
\hline & Sedentary lifestyle & 0.617 & $1.2(0.4-3.5)$ & 0.70 & $1.1(0.5-2.7)$ \\
\hline & Neurological event & 0.896 & $0.9(0.2-3.6)$ & 0.70 & $1.5(0.5-4.6)$ \\
\hline & \multicolumn{5}{|l|}{ Performance } \\
\hline & \multicolumn{2}{|c|}{ Hosmer-Lemeshow $\chi^{2 *}$ (without sedentary lifestyle) } & $12.5(0.126)$ & & $5.9(0.656)$ \\
\hline & \multicolumn{2}{|c|}{ Hosmer-Lemeshow $\chi^{2 *}$ (with sedentary lifestyle) } & $9.9(0.267)$ & & $4.4(0.881)$ \\
\hline
\end{tabular}


were identified as independent predictors for hospital mortality as well as for early mortality. For early mortality, also female gender and a poor left ventricular function are identified as significant and independent predictors. It must be noted, however, that several variables tend to approach significance level (a $p$-value just above 0.05). Our observation that a sedentary lifestyle has a negative influence on survival after cardiac surgery is supported by the Hosmer-Lemeshow test. Large values of the $\chi^{2}$ test and small $p$-values indicate a lack of fit of the model. A $p$-value $>0.05$ means, as in our analysis, a good fit of the model. The increase of the $p$-value after adding 'sedentary lifestyle' as a variable into our model indicates that the observed and expected number of events is more close.

There are several possible reasons why, in our study, a sedentary lifestyle is not identified as an independent variable for hospital mortality and early mortality. Firstly, the CCHP questionnaire used is possibly not specific enough to identify patients with a sedentary lifestyle. Tests as gait speed and hand grip strength are certainly more specific. However, these tests take up extra time in the work-up of the patients undergoing cardiac surgery, whilst the CCHP represents a user-friendly and less time-consuming assessment of a sedentary lifestyle. Secondly, our study included all patients undergoing cardiac surgery during the studied period, including subjects with high and low risk. This is a marked contrast with others, who typically included only older or high-risk patients in their analysis. This point is supported by Fig. 1, where the hospital and early mortality in high-risk patients with a sedentary lifestyle is about two times higher than in high-risk patients with an active lifestyle.

A point of criticism is that the prevalence of our primary outcome parameters (i.e. hospital mortality and early mortality) is relatively low. However, if elective surgery can be performed with such a low mortality rate, the impact of sedentary behaviour on mortality may be of less importance compared with a situation with a higher risk operation. A following question is if the study population is representative. Our patient population has a mean age of 68 years, with $\sim 30 \%$ of the patients being older than 75 years. This is in good agreement with the overall trend we see in all Dutch Heart centres [17]. The risk of mortality calculated by the EuroSCORE seems to be somewhat low, which may relate to the inclusion of elective operations only in our study. If we compare the calculated logistic EuroSCORE of our total population (elective and not-elective patients), we see that our logistic EuroSCORE risk is not different from the calculated risk of patients undergoing cardiac surgery in the Netherlands. (http://www.umcn.nl/Zorg/ Prestaties/Pages/Bypassoperatie.aspx-aortaklepchirurgie.aspx) Therefore, it is unlikely that the included elective patient population is different from the patient population operated electively in the Netherlands nowadays. Another point is that we evaluated only hospital mortality and early mortality. This ignores the fact that occurrence of an event directly related to a cardiac operation can be up to X months after surgery [18]. The importance of a longer follow-up after cardiac surgery to evaluate the potential risks of cardiac surgery is supported by several other reports $[19$, 20] and was recently confirmed by Siregar et al. (Siregar S, Groenwold RH, de Mol BAJM, et al. Evaluation of cardiac surgery mortality rates; 30-day mortality or longer follow-up? Eur J Cardiothorac Surg - accepted for publication).

In conclusion, a sedentary lifestyle, identified by the CCHP questionnaire, appears to be a significant predictor for increased morbidity, hospital mortality and early mortality after elective cardiac surgery. However, sedentary behaviour could not be identified as an independent predictor for hospital or early mortality after elective cardiac surgery. Specific research in high-risk patients seems indicated.

Acknowledgments Dick Thijssen is thanked for his correction of the English text.

Funding None.

Conflict of interests None declared.

Open Access This article is distributed under the terms of the Creative Commons Attribution License which permits any use, distribution, and reproduction in any medium, provided the original author(s) and the source are credited.

\section{References}

1. Wennberg P, Lindahl B, Hallmans G, et al. The effects of commuting activity and occupational and leisure time physical activity on risk of myocardial infarction. Eur J Cardiovasc Prev Rehabil. 2006;13:924-30.

2. Held C, Iqbal R, Lear SA, et al. Physical activity levels, ownership of goods promoting sedentary behaviour and risk of myocardial infarction: results of the INTERHEART study. Eur Heart J. 2012;33:452-66.

3. Steffen-Batey L, Michaman MZ, Goff DC, et al. Change in level of physical activity and risk of all cause mortality or reinfarction. The Corpus Christi Heart Project. Circulation. 2000;102:2204-9.

4. Wright DJ, Williams SG, Riley R, et al. Is early, low level, short term execise cardiac rehabilitation following coronary bypass surgery beneficial? A randomized controlled trial. Heart. 2002;88:83-4.

5. Van der Peijl ID, Vliet Vlieland TPM, Versteegh MIM, et al. Exercise therapy after coronary artery bypass graft surgery: a randomized comparison of a high and low frequency exercise therapy program. Ann Thorac Surg. 2004;77:1535-41.

6. Papaspyros S, Uppal S, Khan SA, et al. Analysis of bedside entertainment services'effect on post cardiac surgery physical activity: a prospective, randomized clinical trial. Eur J Cardiothorac Surg. 2008;34:1022-6.

7. Afilalo J, Eisenberg MJ, Morin J-F, et al. Gait speed as an incremental predictor of mortality and major morbidity in elderly patients undergoing cardiac surgery. J Am Coll Cardiol. 2010;56:1668-76.

8. Nashef SA, Roques F, Sharples LD, et al. EuroSCORE II. Eur J Cardiothorac Surg. 2012;41:734-45.

9. Noyez L, Kievit PC, van Swieten HA, et al. Cardiac operative risk evaluation: The EuroSCORE II, does it make a real difference? Neth Heart J. 2012;20:494-8.

10. Wouters CW, Noyez L. Is no news good news? Organized followup, an absolute necessity for the evaluation of myocardial revascularization. Eur J Cardiothorac Surg. 2004;26:667-70. 
11. Nashef SA, Roques F, Michel P, et al. European system for cardiac preoperative risk evaluation (EuroSCORE). Eur J Cardio-thorac Surg. 1999;16:9-13.

12. Markou ALP, van der Windt A, van Swieten HA, et al. Changes in quality of life, physical activity, and symptomatic status one year after myocardial revascularization for stable angina. Eur J Cardiothorac Surg. 2008;34:1009-15.

13. Hosmer DW, Lemeshow S. Applied logistic regression. New York, NY: John Wiley and Sons; 1989.

14. O'Brien SM, Shadian DM, DeLong ER, et al. Quality measurement in adult cardiac surgery: part 2-Statistical considerations in composite measure scoring and provider rating. Ann Thorac Surg. 2007;83:13-26.

15. van Straten AHM, Soliman Hamad MA, Koene BMJ, et al. Which method of estimating renal function is the best predictor of mortality after coronary artery bypass grafting? Neth Heart J. 2011;19:464-9.
16. Noyez L. Influence of the definition of acute renal failure postcardiac surgery on incidence, patient identification, and identification of risk factors. Eur J Cardiothorac Surg. 2011;39:e8-e12.

17. Hartchirurgie. De Nederlandse Dataregistratie hartchirurgie. Resultaten van samenwerking tussen 16 Nederlandse hartchirurgische centra. Nederlandse Vereniging voor Thoraxchirurgie 2012

18. Noyez L, Verheugt FWA, Peppelenbosch AG, et al. Aortocoronaire bypasschirurgie: voor oordeel over postoperatief beloop follow-up nodig gedurende tenminste een half jaar. Ned Tijdschr Geneeskd. 2000;144:1874-7.

19. De Waard GA, Jansen EK, de Mulder M, et al. Long-term outcomes of isolated aortic valve replacement and concomitant AVR and coronary artery bypass grafting. Neth Heart J. 2012;20:110-7.

20. Algra SO, Breurs JMPJ, Evens FCM, et al. Improving surgical outcome following the Norwood procedure. Neth Heart J. 2011;19:369-72. 